\title{
Journal of the American Medical Directors Association \\ Predictive accuracy of frailty tools for adverse outcomes in a cohort of adults 80 years and older: a decision curve analysis \\ --Manuscript Draft--
}

\begin{tabular}{|c|c|}
\hline Manuscript Number: & JAMDA-D-19-00491R2 \\
\hline Article Type: & Original Study \\
\hline Keywords: & adults 80 years or older; frailty; decision curve analysis \\
\hline Corresponding Author: & $\begin{array}{l}\text { Eralda Hegendörfer, M.D.,Ph.D } \\
\text { KULeuven \& UCLouvain } \\
\text { Leuven, BELGIUM }\end{array}$ \\
\hline First Author: & Eralda Hegendörfer, M.D.,Ph.D \\
\hline \multirow[t]{6}{*}{ Order of Authors: } & Eralda Hegendörfer, M.D.,Ph.D \\
\hline & Bert Vaes \\
\hline & Gijs Van Pottelbergh \\
\hline & Catharina Mathei \\
\hline & Jan Verbakel \\
\hline & Jean-Marie Degryse \\
\hline Abstract: & $\begin{array}{l}\text { Objectives: To compare the predictive performance of three frailty identification tools } \\
\text { for mortality, hospitalization and functional decline in adults aged } \geq 80 \text { years using risk } \\
\text { reclassification statistics and decision curve analysis. } \\
\text { Design: Population-based, prospective cohort } \\
\text { Setting: BELFRAIL study, Belgium } \\
\text { Participants: } 560 \text { community-dwelling adults aged } \geq 80 \text { years. } \\
\text { Measurements: Frailty by Cardiovascular Health Study (CHS) phenotype, Longitudinal } \\
\text { Aging Study Amsterdam (LASA) markers and Groeningen Frailty Indicator (GFI). } \\
\text { Mortality until } 5.1 \pm 0.25 \text { years from baseline and hospitalization until } 3.0 \pm 0.25 \text { years. } \\
\text { Functional status assessed by activities of daily living at baseline and after } 1.7 \pm 0.21 \\
\text { years. } \\
\text { Results: Frailty prevalence: } 7.3 \% \text { by CHS phenotype, } 21.6 \% \text { by LASA markers and } \\
22 \% \text { by GFI. Frail participants by each tool had significantly higher risk for all-cause } \\
\text { mortality and first hospitalization. For functional decline, only frail by GFI had higher } \\
\text { adjusted odds ratio. Harrell's C statistic for mortality and hospitalization and area under } \\
\text { receiver operating characteristic curve for functional decline were similar for all tools } \\
\text { and }<0.70 \text {. Reclassification statistics showed improvement only by LASA markers for } \\
\text { hospitalization and mortality. In decision curve analysis, all tools had higher net benefit } \\
\text { than two default strategies of 'treat all' and 'treat none' for mortality risk } \geq 20 \% \text {, } \\
\text { hospitalization risk } \geq 35 \% \text { and functional decline probability } \geq 10 \% \text {, but their curves } \\
\text { overlapped across all relevant risk thresholds for these outcomes. } \\
\text { Conclusions and Implications: In a cohort of adults aged } \geq 80 \text { years three frailty tools } \\
\text { based on different conceptualizations and assessment sources had comparable but } \\
\text { unsatisfactory discrimination for predicting mortality, hospitalization and functional } \\
\text { decline. All showed clinical utility for predicting these outcomes over relevant risk } \\
\text { thresholds, but none was significantly superior. Future research on frailty tools should } \\
\text { include a focus on the specific group of adults aged } \geq 80 \text { years and the predictive } \\
\text { accuracy for adverse outcomes of different tools needs a comprehensive assessment } \\
\text { that includes decision curve analysis. }\end{array}$ \\
\hline
\end{tabular}


Title: Predictive accuracy of frailty tools for adverse outcomes in a cohort of adults 80 years and older: a decision curve analysis

Authors: Eralda Hegendörfer ${ }^{1,2}$, Bert Vaes ${ }^{1}$, Gijs Van Pottelbergh ${ }^{1}$, Catharina Matheï ${ }^{1}$, Jan Verbakel ${ }^{1,3}$, Jean-Marie Degryse ${ }^{1,2}$

Affiliations: ${ }^{1}$ Department of Public Health and Primary Care, Katholieke Universiteit Leuven (KULeuven), Belgium; ${ }^{2}$ Institute of Health and Society, Université Catholique de Louvain (UCLouvain), Belgium; ${ }^{3}$ Nuffield Department of Primary Care Health Sciences, University of Oxford, United Kingdom

Corresponding author: Eralda Hegendörfer

Address: Academic Center for General Practice KU Leuven, Kapucijnenvoer 33 blok j-box 7001, 3000 Leuven; Email: eralda.turkeshi@kuleuven.be

Running title: Frailty tools in adults 80 years and older

Word count: 2956

Reference count: 49

Table/Figure count: 5

Brief summary: In a cohort of adults 80 years or older, three frailty tools showed positive net benefit in decision curve analysis for identifying higher risk for adverse outcomes, but predictive accuracy was limited and no tool was robustly superior.

Funding Sources: The BELFRAIL study was supported by an unconditional grant from Fondation Louvain, Brussels, Belgium (grant number B40320084685).

Acknowledgements: The authors would like to acknowledge all the general practitioners that recruited and followed-up their patients in the BELFRAIL study.

Ethical approval: The study protocol was approved by the Biomedical Ethics Committee of the Medical School of the Universite catholique de Louvain, Belgium. All participants gave informed consent. 


\section{ABSTRACT}

Objectives: To compare the predictive performance of three frailty identification tools for mortality, hospitalization and functional decline in adults aged $\geq 80$ years using risk reclassification statistics and decision curve analysis.

Design: Population-based, prospective cohort

Setting: BELFRAIL study, Belgium

Participants: 560 community-dwelling adults aged $\geq 80$ years.

Measurements: Frailty by Cardiovascular Health Study (CHS) phenotype, Longitudinal Aging

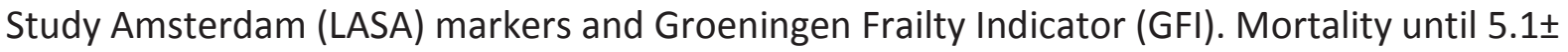
0.25 years from baseline and hospitalization until $3.0 \pm 0.25$ years. Functional status assessed by activities of daily living at baseline and after $1.7 \pm 0.21$ years.

Results: Frailty prevalence: $7.3 \%$ by CHS phenotype, $21.6 \%$ by LASA markers and $22 \%$ by GFI. Frail participants by each tool had significantly higher risk for all-cause mortality and first hospitalization. For functional decline, only frail by GFI had higher adjusted odds ratio. Harrell's C statistic for mortality and hospitalization and area under receiver operating characteristic curve for functional decline were similar for all tools and $<0.70$. Reclassification statistics showed improvement only by LASA markers for hospitalization and mortality. In decision curve analysis, all tools had higher net benefit than two default strategies of 'treat all' and 'treat none' for mortality risk $\geq 20 \%$, hospitalization risk $\geq 35 \%$ and functional decline probability $\geq 10 \%$, but their curves overlapped across all relevant risk thresholds for these outcomes. 
Conclusions and Implications: In a cohort of adults aged $\geq 80$ years three frailty tools based on different conceptualizations and assessment sources had comparable but unsatisfactory discrimination for predicting mortality, hospitalization and functional decline. All showed clinical utility for predicting these outcomes over relevant risk thresholds, but none was significantly superior. Future research on frailty tools should include a focus on the specific group of adults aged $\geq 80$ years and the predictive accuracy for adverse outcomes of different tools needs a comprehensive assessment that includes decision curve analysis. 


\section{INTRODUCTION}

Due to worldwide population ageing and variability of ageing trajectories, the concept of frailty has become increasingly important. ${ }^{1,2}$ Frailty identification is recommended due to its association with adverse outcomes such as falls, functional decline, institutionalization, hospitalization, death, and its potential reversibility and prevention. ${ }^{2,3}$ While understanding the complexity and heterogeneity of frailty has grown, there is still no widespread consensus on its conceptualization and assessment. ${ }^{1,3,4}$ Two main frailty approaches, as uni-dimensional physical phenotype or multidimensional deficit accumulation index, have been widely used in older adults. ${ }^{1-3,5,6}$ Many tools have been developed to identify frailty (up to 67 according to a recent review) ${ }^{7}$, yet their validation and accuracy is not adequate. ${ }^{1 \text {, }}$ 6-11

In the past few years, several studies have compared different frailty tools for their predictive ability of adverse outcomes in older adults in different settings. ${ }^{8,12-20}$ One common way of comparing competing risk prediction models is through assessing their discrimination by the concordance (C) -statistic either as area under the receiver operating characteristic curve (AUC) for binary outcomes or Harrell's C for time-dependent outcomes.

${ }^{21}$ As C-statistic does not capture the extent of change in predicted risk between competing models and its clinical utility, risk reclassification statistics and decision curve analysis have been proposed and used as complimentary to evaluate discrimination improvement and clinical utility of prediction models. ${ }^{22-25}$ So far the comparison of different frailty tools has only been based on odds (OR) or hazard ratios (HR) and AUCs. ${ }^{14,16-19,26,27}$ Additionally, there is a lack of studies of different frailty tools in community-dwelling older adults aged 
$\geq 80$ years, the fastest growing group of older adults, where the accuracy of current frailty tools could improve due to a higher expected prevalence. ${ }^{10,28}$

This study aims to apply and compare the predictive performance of three frailty tools for all-cause mortality, first unplanned hospitalization and functional decline in a communitybased prospective cohort of adults aged 80 years and older using risk reclassification statistics and decision curve analysis. 


\section{METHODS}

\section{Study design and population}

BELFRAIL is a population-based, prospective cohort of adults aged 80 and over in Belgium. The study protocol has been previously published. ${ }^{29}$ Briefly, from November 2008 until September 2009, 567 individuals aged $\geq 80$ years were randomly recruited in 29 general practices, excluding those with severe dementia, in palliative care or medical emergencies. At baseline, general practitioners recorded socio-demographic and medical history data and performed a standardized physical examination. Two trained clinical research assistants performed at-home standardized comprehensive assessments at baseline and after $1.7 \pm$ 0.21 years. Data on hospitalization were collected until $3.0 \pm 0.25$ years and on mortality until $5.1 \pm 0.25$ years from baseline (Figure 1 ).

\section{Frailty identification tools}

Three frailty tools were used: the Cardiovascular Health Study (CHS) frailty phenotype, ${ }^{30}$ the Longitudinal Aging Study Amsterdam (LASA) frailty markers ${ }^{31}$ and the Groeningen Frailty Indicator (GFI) ${ }^{32}$. They represent the two frailty approaches: uni-dimensional physical phenotype (CHS phenotype) and multi-dimensional deficit accumulation (LASA markers and GFI). They also cover different assessment sources: self-report (GFI) and performance-based or mixed (CHS phenotype and LASA markers).

The CHS frailty phenotype has 5 components: weight loss, exhaustion, weakness, slowness and low physical activity ${ }^{30}$ (see Appendix). The nine LASA frailty markers include low body mass index, low peak flow, low mini mental status examination score, urinary incontinence, poor vision or hearing, low mastery/resilience, depression and low physical activity ${ }^{31}$ (see Appendix). For both CHS phenotype and LASA markers, participants with three or more 
components were considered frail. ${ }^{30,31}$ The GFI was part of the standardized assessment in the BELFRAIL study. ${ }^{29}$ It is a 15 -items questionnaire covering self-reported limitations in physical (nine items), cognitive (one item), psychological (two items) and social (three items) domains ${ }^{33}$ (see Appendix). Scores range from 0 to 15 and those with scores $\geq 5$ were considered frail. We also investigated 'frail by any' if frail by at least one of the three tools.

\section{Outcomes}

Time to all-cause death and first, un-planned hospitalisation, and functional decline were outcome measurements. The date and cause of hospitalization and death were prospectively reported by the general practitioners. Activities of daily living measured functional limitation. At baseline and follow-up visits, participants described the degree of difficulty with six activities: climbing stairs, walking 5 minutes outdoors without resting, getting up and sitting down in a chair, dressing and undressing oneself, using own or public transport and cutting one's own nails. The response categories ranged from 1 ('No I cannot') to 5 ('Yes, without difficulty') with total score of $6-30 .{ }^{29}$ Functional decline was defined as a decrease of at least $20 \%$ from baseline score.

\section{Other variables}

Age, sex and multimorbidity were used as confounders of the association of frailty with mortality, hospitalization and functional decline. Multimorbidity was assessed with the unweighted disease count of morbidities reported by the general practitioners at baseline (see Appendix).

\section{Statistical analysis}

Comparisons of baseline and outcome variables between frail and robust participants by each tool were tested with independent Student's $t$ test (parametric variables), Mann- 
Whitney U test (non-parametric) and Pearson's Chi-squared test (categorical). Agreement between the tools for identifying frail participants was measured with Cohen's kappa coefficient and displayed graphically with Venn diagram.

Kaplan-Meier curves for all-cause mortality and hospitalization were plotted for each frailty tool using the log-rank test for comparison between frail and robust groups. HRs for mortality and first hospitalization with adjustment for age, sex and multimorbidity were estimated with Cox proportional hazards regression models. Models were checked for the proportional hazard assumption. ORs for functional decline were estimated with logistic regression model. The robust group was the reference. Variables were checked for multicollinearity. A two-tailed probability value $p<0.05$ was considered statistically significant.

Harrell's C, AUCs, continuous net reclassification improvement (NRI), integrated discrimination improvement (IDI) and decision curve analysis were used to compare the predictive value and clinical utility of frailty tools. Individual predicted absolute risks (mortality and hospitalization) and probability (functional decline) were calculated for frail by each tool based on regression coefficients. ${ }^{21}$ For NRI and IDI, frail by CHS phenotype was used as reference. The continuous NRI is the sum of NRI events and NRI non-events, without a defined risk category. NRlevents is percentage of participants with event (death, hospitalization, functional decline) who were assigned a higher risk/probability by the alternative tool. The NRI non-events is percentage of participants without events who were assigned a lower risk/probability by the alternative tool. NRI is considered as sum of improvement in sensitivity ( $\left.N R l_{\text {event }}\right)$ and specificity ( $\left.N R I_{\text {non-events }}\right)$. IDI is the difference of discrimination slopes (difference of mean predicted risk/probability of participants with and 
without events) between reference and alternative tools. Relative IDI is IDI over the discrimination slope of the reference tool. ${ }^{22}$ It is interpreted as the amount by which the alternative tool increases the separation of mean predicted risk/probability for events and non-events. ${ }^{22}$ Net benefit is the difference between true-positives and false-positives, weighted by the relative harm of false-positives for a chosen risk/probability threshold. ${ }^{24,25}$ For decision curve analysis, the net benefit if participants are treated according to risk assigned by frail by each tool is plotted across the range of risks/probabilities for an event and compared to two default management strategies if no tool is used: (1) consider all participants as frail and apply an intervention ('treat all') or consider all non-frail and apply no intervention ('treat none'). ${ }^{24}$ Frailty by a tool has clinical utility if its net benefit curve is above that of 'treat all' or 'treat none' for a range of reasonable risk thresholds. The tool with higher net benefit for a certain risk/probability has more clinical utility. ${ }^{24}$ Statistical analysis was performed with SPSS 25.0 (SPSS Inc., Chicago, IL, USA), Stata 15.0 (StataCorp., College Station, TX, USA) and SAS University Edition (SAS Institute Inc., Cary, NC, USA). 


\section{RESULTS}

\section{Baseline characteristics of the study population}

Out of the 567 participants of the BELFRAIL cohort, 560 had a baseline assessment that included GFI (559 participants) and valid measurements of CHS phenotype components (532) and LASA markers (501) (Figure 1). Frailty prevalence was 7.3\% by CHS phenotype, $22 \%$ by GFI and $21.6 \%$ by LASA markers. Frail participants by each tool had statistically significant worse values for activities of daily living, depression, mental status, physical activity, grip strength and walking time. They were also older and (except for frail by CHS phenotype) consisted of more females and had higher multimorbidity (Table 1).

\section{Agreement between frailty tools}

Out of 177 frail participants by any tool, only $23(13 \%)$ were frail by all three (Figure 2). The highest concordance was between LASA markers and GFI ( $48.8 \%$ of frail by GFI were also frail by LASA markers and $55.5 \%$ vice versa). Within the frail by CHS phenotype, $59 \%$ were frail by either LASA or GFI, while CHS phenotype identified only $22.8 \%$ of frail by GFI and $25.9 \%$ of frail by LASA markers. Cohen's kappa coefficients showed moderate agreement between GFI and LASA markers $(0.4595 \% \mathrm{Cl} 0.32-0.50)$ and only fair agreement between CHS phenotype and GFI $(0.29,95 \% \mathrm{Cl} 0.20-0.39)$ or LASA markers $(0.35,95 \% \mathrm{Cl} 0.24-0.45)$.

\section{All-cause mortality and hospitalization}

All-cause mortality data were available for all participants, while first unplanned hospitalization data were missing for 7 participants. During $3.0 \pm 0.25$ years, $284(50.7 \%)$ had at least one unplanned hospitalization and at $5.1 \pm 0.25$ years $237(42.3 \%)$ had died (Table 1$)$. For each tool, frail participants had significantly higher all-cause mortality and first hospitalization compared to robust ones (Figure 3), even after adjustment (Table 2). 
Harrell's C for all-cause mortality ranged from 0.65 (95\% Cl 0.61-0.68) for CHS phenotype or GFI to 0.67 (95\% Cl 0.63-0.70) for 'frail by any'. For first hospitalization the range was 0.64 (95\% $\mathrm{Cl} 0.61-0.68)$ for CHS phenotype or GFI to $0.65(95 \% \mathrm{Cl} 0.62-0.69)$ for LASA markers or 'frail by any' (Table 2).

Based on NRI, compared to CHS phenotype the LASA markers improved risk classification for $75 \%$ of alive participants and worsened it for $49.5 \%$ of deceased ones, while 'frail by any ' improved it for $60.9 \%$ of alive participants and worsened it for $21 \%$ of the deceased (Table 3). For hospitalization, only LASA markers improved risk classification for $80.2 \%$ of those without hospitalization and worsened it for $64 \%$ of those with hospitalization. Only LASA markers and 'frail by any' had a statistically relevant higher IDI for both mortality and hospitalization, increasing the difference of the mean predicted risk of events (death/hospitalization) and non-events (alive/no hospitalization) with those of the CHS phenotype by $31.6 \%$ (LASA markers) and $46.2 \%$ ('frail by any ') for mortality, and $18.4 \%$ (LASA markers) and $18.2 \%$ ('frail by any ') for first hospitalization (Table 3). In decision curve analysis, frail by each tool had a net benefit superior to 'treat all' or 'treat none' for mortality risk $\geq 20 \%$ and hospitalization risk $\geq 35 \%$. Net benefit curves for each tool overlapped considerably across relevant mortality and hospitalization risk thresholds (Figure 4).

\section{Functional decline}

Data on functional decline at $1.7 \pm 0.21$ years follow-up were available for 421 participants and 66 (15.7\%) had declined at least 20\% from baseline score. Only frail by GFI and 'frail by any' had statistically significant increased adjusted ORs for functional decline (Table 2). All tools had similar AUCs ranging from 0.65 (95\% Cl 0.57-0.73) for LASA markers to 0.69 (95\% Cl 0.62-0.76) for 'frail by any' (Table 2). 
Based on NRI, only the 'frail by any' improved risk classification for $57.5 \%$ of those without functional decline and worsened it for $23.3 \%$ of those with decline compared to CHS phenotype (Table 3). No tool showed any improvement compared to the CHS phenotype based on IDI. In decision curve analysis, frail by each tool had higher net benefit than 'treat all' or 'treat none' for $\geq 10 \%$ predicted probability for functional decline. Net benefit curves of all tools overlapped (Figure 4). 


\section{DISCUSSION}

In a cohort of community-dwelling adults aged $\geq 80$ years we applied CHS phenotype, LASA markers and GFI and found different frailty prevalence, with fair to moderate agreement between the tools. All tools had higher net benefit than two default strategies of 'treat all' and 'treat none' for 5-years mortality risk $\geq 20 \%$, 3-years hospitalization risk $\geq 35 \%$ and 2 years functional decline probability $\geq 10 \%$. Yet their net benefit curves overlapped across all relevant risk thresholds.

We could not find studies that had applied and compared different frailty tools in community-dwelling adults aged $\geq 80$ years. In our cohort, frailty prevalence was nearly three times higher by GFI and LASA markers compared to CHS phenotype, confirming previous reports of higher prevalence with multidimensional tools. ${ }^{13,} 18,28,34$ We found lower prevalence than that expected in this age-group by previous research (weighted average prevalence of $16 \%$ for $80-84$ years old and $26 \%$ for $\geq 85$ years based on 4 studies of community-dwelling adults $\geq 65$ years old with age-stratified prevalence, 3 of which used the CHS phenotype). ${ }^{2,28}$ Differences in frailty prevalence (even when using the same tool) have been previously reported and could reflect differences in study designs, measures of tool components and ageing trajectories. ${ }^{35-37}$ Furthermore, adults aged $\geq 80$ years are survivors of their generation and may show reversed epidemiology. ${ }^{38,39}$ The frailty cut-offs of different tools are also based on studies in younger old adults and different cut-offs may be needed in different age-groups or settings of older adults. ${ }^{2}$ As expected, the highest but still moderate agreement was between the multidimensional tools, GFI and LASA markers. Despite being both multidimensional, GFI is based only on self-report while LASA markers 
include performance measures (pulmonary function) and scores of validated scales for mental status, depression, resilience and physical activity. ${ }^{31,33}$

Previous studies on the predictive performance of different frailty tools have compared mainly ORs/HRs and AUCs. ${ }^{6,27}$ In a large comparative study of frailty tools among adults 50 years and older in 11 European countries (mean age 65.3), the AUC for 5-years mortality were similar for GFI $(0.70(0.69-0.72))$ and CHS phenotype $\left((0.70(0.68-0.71)) .{ }^{13} \mathrm{In}\right.$ a recent comparison study in a Canadian cohort of community-dwelling older adults (mean age 77.7) the AUCs for 2-years mortality were 0.69 for CHS phenotype and 0.61 for GFI and for disability 0.68 and 0.66 , respectively. ${ }^{18}$ We found that HRs and Harrell's C for mortality and hospitalization and ORs and AUCs for functional decline were not significantly different between frailty tools. As in previous studies, Harrell's C and AUC were less than 0.70 so lacking good discrimination. ${ }^{18,40}$ Based on reclassification statistics (NRI and IDI), LASA markers performed better than CHS phenotype for mortality and hospitalization, mainly due to improved specificity. This could be explained by the multidimensional LASA markers and inclusion of pulmonary function that is associated with frailty and adverse outcomes in older adults. ${ }^{2,41}$ Decision curve analysis, which assesses clinical utility of prediction models, showed that if we apply frailty interventions for predicted risks of $\geq 20 \%$ for 5 -years mortality, $\geq 35 \%$ for 3-years hospitalization and $\geq 10 \%$ probability of 2-years functional decline, then all tools would have clinical value as at these thresholds they are better than 'treat all' and 'treat none' alternatives. Yet no tool was superior as net benefit curves overlapped across all relevant risk thresholds. These findings in our cohort of adults aged $\geq 80$ years confirm that although the different frailty tools have clinical utility in identifying 
older adults with higher risk for adverse outcomes, their predictive accuracy is limited and none stands out as the best tool consistently and through a variety of relevant outcomes.

One of the strengths of this study is the design of BELFRAIL as a population-based prospective cohort of community-dwelling adults aged $\geq 80$ years with data on mortality, first hospitalization and functional decline. The comprehensive BELFRAIL assessment allowed the application of three frailty tools that represent different approaches and assessment sources. We also extended the comparison of their predictive ability beyond the binary AUCs including time-dependent C-statistic, risk reclassification and decision curve analysis that are commonly used for risk prediction models. ${ }^{42}$ The measurement modifications for some components of frailty tools is a weakness, yet unavoidable and common in previous research as well. ${ }^{11,37}$ We used the CHS phenotype as a reference for calculating NRI and IDI, while the comprehensive geriatric assessment is considered as gold standard assessment for frailty. ${ }^{2}$ As expected in a cohort of very old adults, we had loss of data for functional decline due to mortality between the two assessments.

\section{CONCLUSIONS AND IMPLICATIONS}

In conclusion, in our cohort of community-dwelling adults aged $\geq 80$ years, three frailty tools representing different frailty approaches and assessment sources showed clinical utility for identifying higher risk for functional decline, unplanned hospitalization and all-cause mortality based on decision curve analysis, but their predictive accuracy was limited and none was robustly superior.

Future research on frailty tools should include a focus on adults aged $\geq 80$ years that have been underrepresented so far. Although there is no consensus on which frailty tool to use, 
those based on the multi-dimensional deficit accumulation approach are preferred and seem to perform better. ${ }^{2,14,16,43,44}$ Frailty indexes with a list of health deficits including common laboratory tests have been recently developed and validated and need to be tested in adults aged $\geq 80$ years. ${ }^{45-47}$ Due to the multidimensionality and heterogeneity of frailty, it is reasonable to use different tools for different outcomes, settings and populations of older adults rather than pursue a 'one size fits all' approach. ${ }^{4,11,48,49}$ Future research on frailty tools should move beyond sensitivity, specificity and AUCs and report reclassification statistics and decision curve analysis for different outcomes, for a more comprehensive and clinically relevant evaluation. ${ }^{24,26,42}$ While waiting for further research on frailty tools in adults aged $\geq 80$ years, clinical practitioners may choose the easiest-to-use tool in their setting, as identifying frailty by any tool in our study was more beneficial than treating all or none as frail. 


\section{REFERENCES}

1. Sloane PD, Cesari M. Research on Frailty: Continued Progress, Continued Challenges. J Am Med Dir Assoc 2018;19(4):279-81.

2. Clegg A, Young J, lliffe S, Rikkert MO, Rockwood K. Frailty in elderly people. The Lancet 2013;381(9868):752-62.

3. Morley JE, Vellas B, van Kan GA, et al. Frailty consensus: a call to action. J Am Med Dir Assoc 2013;14(6):392-7.

4. Looman WM, Fabbricotti IN, Blom JW, et al. The frail older person does not exist: development of frailty profiles with latent class analysis. BMC Geriatr 2018;18(1):84.

5. Rockwood K, Howlett SE. Fifteen years of progress in understanding frailty and health in aging. BMC Med 2018;16(1):220-20.

6. Bouillon K, Kivimaki M, Hamer M, et al. Measures of frailty in population-based studies: an overview. BMC Geriatr 2013;13:64.

7. Buta BJ, Walston JD, Godino JG, et al. Frailty assessment instruments: Systematic characterization of the uses and contexts of highly-cited instruments. Ageing Res Rev 2016;26:53-61.

8. de Vries NM, Staal JB, van Ravensberg CD, et al. Outcome instruments to measure frailty: a systematic review. Ageing Res Rev 2011;10(1):104-14.

9. Xue QL, Varadhan R. What is missing in the validation of frailty instruments? J Am Med Dir Assoc 2014;15(2):141-2.

10. Clegg A, Rogers L, Young J. Diagnostic test accuracy of simple instruments for identifying frailty in community-dwelling older people: a systematic review. Age Ageing 2015;44(1):14852.

11. Dent E, Kowal P, Hoogendijk EO. Frailty measurement in research and clinical practice: A review. Eur J Intern Med 2016;31:3-10. 
12. Daniels R, van Rossum E, Beurskens A, et al. The predictive validity of three self-report screening instruments for identifying frail older people in the community. BMC Pub Health 2012;12(1):69.

13. Theou O, Brothers TD, Mitnitski A, Rockwood K. Operationalization of frailty using eight commonly used scales and comparison of their ability to predict all-cause mortality. J Am Geriatr Soc 2013;61(9):1537-51.

14. Sutorius FL, Hoogendijk EO, Prins BA, van Hout HP. Comparison of 10 single and stepped methods to identify frail older persons in primary care: diagnostic and prognostic accuracy. BMC Fam Pract 2016;17:102.

15. Hoogendijk EO, van der Horst HE, Deeg DJ, et al. The identification of frail older adults in primary care: comparing the accuracy of five simple instruments. Age Ageing 2013;42(2):262-5.

16. Malmstrom TK, Miller DK, Morley JE. A Comparison of Four Frailty Models. J Am Geriatr Soc 2014;62(4):721-26.

17. Pijpers E, Ferreira I, Stehouwer CD, Nieuwenhuijzen Kruseman AC. The frailty dilemma. Review of the predictive accuracy of major frailty scores. Eur J Intern Med 2012;23(2):11823.

18. Bongue B, Buisson A, Dupre C, et al. Predictive performance of four frailty screening tools in community-dwelling elderly. BMC Geriatr 2017;17(1):262.

19. Lin SM, Aliberti MJR, Fortes-Filho SdQ, et al. Comparison of 3 Frailty Instruments in a Geriatric Acute Care Setting in a Low-Middle Income Country. J Am Med Dir Assoc 2018;19(4):310-14.e3.

20. Turusheva A, Frolova E, Korystina E, et al. Do commonly used frailty models predict mortality, loss of autonomy and mental decline in older adults in northwestern Russia? A prospective cohort study. BMC Geriatr 2016;16:98. 
21. Moons KG, Kengne AP, Woodward M, et al. Risk prediction models: I. Development, internal validation, and assessing the incremental value of a new (bio)marker. Heart 2012;98(9):68390.

22. Pencina MJ, D'Agostino RB, Sr., Demler OV. Novel metrics for evaluating improvement in discrimination: net reclassification and integrated discrimination improvement for normal variables and nested models. Stat Med 2012;31(2):101-13.

23. Van Calster B, Vickers AJ, Pencina MJ, et al. Evaluation of markers and risk prediction models: overview of relationships between NRI and decision-analytic measures. Med Decis Making 2013;33(4):490-501.

24. Vickers AJ, Van Calster B, Steyerberg EW. Net benefit approaches to the evaluation of prediction models, molecular markers, and diagnostic tests. Br Med J 2016;352:i6.

25. Van Calster B, Wynants L, Verbeek JFM, et al. Reporting and Interpreting Decision Curve Analysis: A Guide for Investigators. Eur Urol 2018;74(6):796-804.

26. Rockwood K, Theou O, Mitnitski A. What are frailty instruments for? Age Ageing 2015;44(4):545-7.

27. Vermeiren S, Vella-Azzopardi R, Beckwée D, et al. Frailty and the Prediction of Negative Health Outcomes: A Meta-Analysis. J Am Med Dir Assoc 2016;17(12):1163.e1-63.e17.

28. Collard RM, Boter H, Schoevers RA, Oude Voshaar RC. Prevalence of frailty in communitydwelling older persons: a systematic review. J Am Geriatr Soc 2012;60(8):1487-92.

29. Vaes B, Pasquet A, Wallemacq P, et al. The BELFRAIL (BFC80+) study: a population-based prospective cohort study of the very elderly in Belgium. BMC Geriatr 2010;10:39.

30. Fried LP, Tangen CM, Walston J, et al. Frailty in older adults: evidence for a phenotype. J Gerontol A Biol Sci Med Sci 2001;56(3):M146-56.

31. Puts MT, Lips P, Deeg DJ. Sex differences in the risk of frailty for mortality independent of disability and chronic diseases. J Am Geriatr Soc 2005;53(1):40-7. 
32. Steverink N, Slaets J, Schuurmans H, Van Lis M. Measuring frailty: Developing and testing the GFI (Groningen Frailty Indicator). Gerontologist 2001;41(Special issue 1):236-37.

33. Schuurmans $\mathrm{H}$, Steverink N, Lindenberg S, et al. Old or frail: what tells us more? J Gerontol A Biol Sci Med Sci 2004;59(9):M962-5.

34. Shamliyan T, Talley KMC, Ramakrishnan R, Kane RL. Association of frailty with survival: A systematic literature review. Ageing Res Rev 2013;12(2):719-36.

35. Wong $\mathrm{CH}$, Weiss $\mathrm{D}$, Sourial $\mathrm{N}$, et al. Frailty and its association with disability and comorbidity in a community-dwelling sample of seniors in Montreal: a cross-sectional study. Aging Clin Exp Res 2010;22(1):54-62.

36. Chen $\mathrm{CY}, \mathrm{Wu} \mathrm{SC}$, Chen $\mathrm{LJ}$, Lue BH. The prevalence of subjective frailty and factors associated with frailty in Taiwan. Arch Gerontol Geriatr 2010;50 Suppl 1:S43-7.

37. Theou O, Cann L, Blodgett J, et al. Modifications to the frailty phenotype criteria: Systematic review of the current literature and investigation of 262 frailty phenotypes in the Survey of Health, Ageing, and Retirement in Europe. Ageing Res Rev 2015;21:78-94.

38. Rapp MA, Gerstorf D, Helmchen H, Smith J. Depression predicts mortality in the young old, but not in the oldest old: results from the Berlin Aging Study. Am J Geriatr Psychiatry 2008;16(10):844-52.

39. de Ruijter W, Westendorp RG, Assendelft WJ, et al. Use of Framingham risk score and new biomarkers to predict cardiovascular mortality in older people: population based observational cohort study. Br Med J 2009;338:a3083.

40. Hosmer DW, Lemeshow S. Applied Logistic Regression. 2nd ed. New York, NY: John Wiley \& Sons, Inc.; 2000.

41. Hegendorfer E, Vaes B, Andreeva E, et al. Predictive Value of Different Expressions of Forced Expiratory Volume in 1 Second (FEV1) for Adverse Outcomes in a Cohort of Adults Aged 80 and Older. J Am Med Dir Assoc 2017;18(2):123-30. 
42. Moons KG, Altman DG, Reitsma JB, et al. Transparent Reporting of a multivariable prediction model for Individual Prognosis or Diagnosis (TRIPOD): explanation and elaboration. Ann Intern Med 2015;162(1):W1-73.

43. Kulminski AM, Ukraintseva SV, Kulminskaya IV, et al. Cumulative deficits better characterize susceptibility to death in elderly people than phenotypic frailty: lessons from the Cardiovascular Health Study. J Am Geriatr Soc 2008;56(5):898-903.

44. Gonzalez-Colaco Harmand M, Meillon C, Bergua V, et al. Comparing the predictive value of three definitions of frailty: Results from the Three-City study. Arch Gerontol Geriatr 2017;72:153-63.

45. Hoogendijk EO, Theou O, Rockwood K, et al. Development and validation of a frailty index in the Longitudinal Aging Study Amsterdam. Aging Clin Exp Res 2017;29(5):927-33.

46. Blodgett JM, Theou O, Howlett SE, Rockwood K. A frailty index from common clinical and laboratory tests predicts increased risk of death across the life course. Geroscience 2017;39(4):447-55.

47. Clegg A, Bates C, Young J, et al. Development and validation of an electronic frailty index using routine primary care electronic health record data. Age Ageing 2018;47(2):319.

48. Cigolle CT, Ofstedal MB, Tian Z, Blaum CS. Comparing models of frailty: the Health and Retirement Study. J Am Geriatr Soc 2009;57(5):830-9.

49. Sternberg SA, Schwartz AW, Karunananthan S, Bergman H, Mark Clarfield A. The Identification of Frailty: A Systematic Literature Review. J Am Geriatr Soc 2011;59(11):212938. 


\section{FIGURE LEGENDS}

Figure 1: Flowchart of the data collection in the BELFRAIL cohort study

ADL: activities of daily living; CHS: Cardiovascular Health Study frailty phenotype; GFI: Groeningen Frailty Indicator, LASA:Longitudinal Aging Study Amsterdam frailty markers

Figure 2: Venn diagram presenting the extent of overlap between the frail participants identified with the three frailty tools (the 177 participants in this diagram are those identified as frail by at least one of the tools)

CHS: Cardiovascular Health Study frailty phenotype; GFI: Groeningen Frailty Indicator, LASA:Longitudinal Aging Study Amsterdam frailty markers

Figure 3: Kaplan-Meier survival curves for 5-years mortality and 3-years hospitalization for frailty by the different tools

CHS: Cardiovascular Health Study; LASA: Longitudinal Amsterdam Study of Ageing;GFI: Groeningen Frailty Indicator. Frail by any: if frail by any of the three tools.

Figure 4: Decision curve analysis of frailty tools for mortality, hospitalization and functional decline

Net benefit curves are plotted across risk/probability thresholds for an event (mortality, hospitalization, functional decline) for 6 options: 'treat all' as if they are frail, 'treat none' considering none is frail, treat according to frailty by CHS phenotype, LASA markers, GFI or if frail by any tool. 


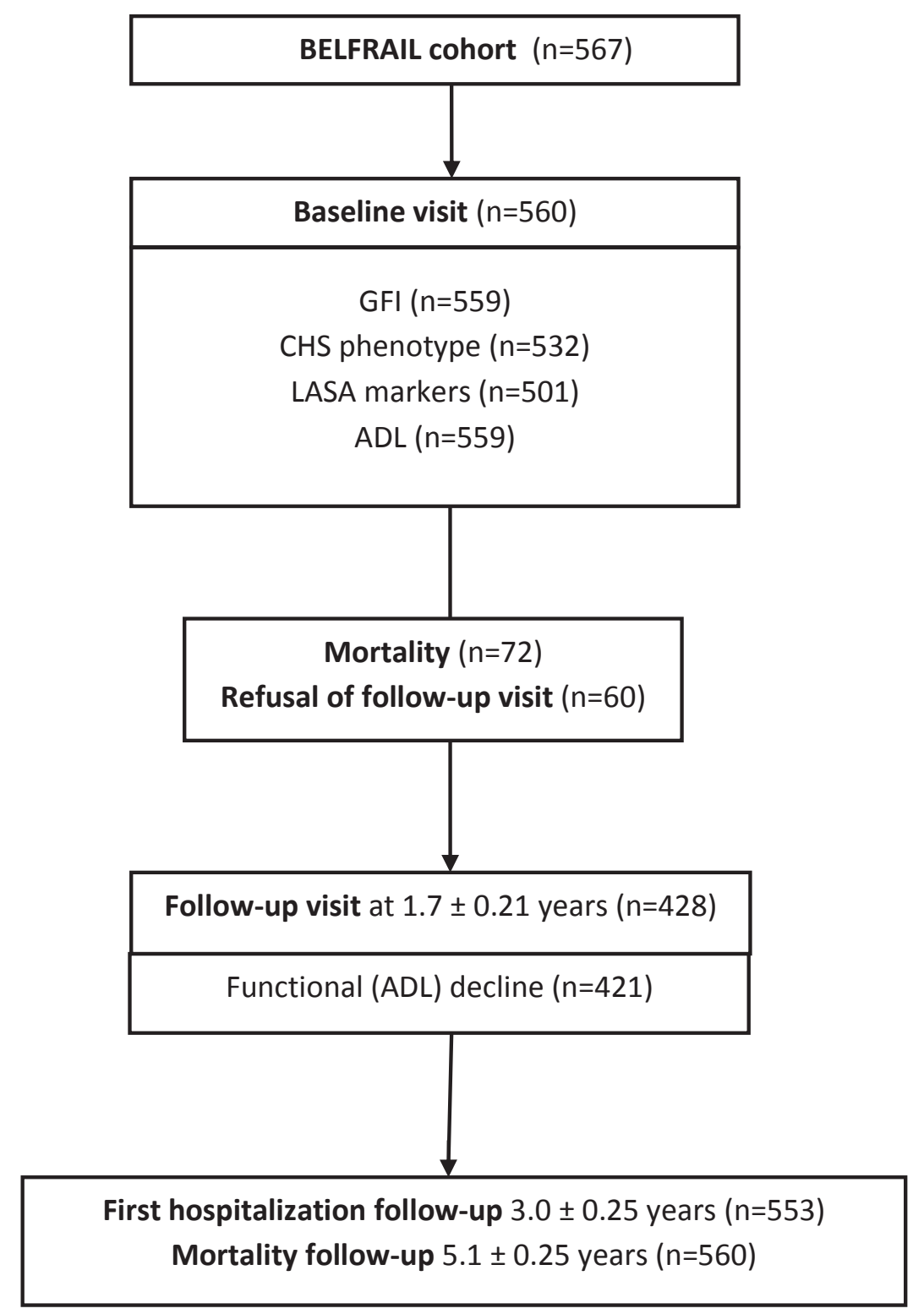

Figure 1: Flowchart of the data collection in the BELFRAIL cohort study

ADL: activities of daily living; CHS: Cardiovascular Health Study frailty phenotype;

GFI: Groeningen Frailty Indicator, LASA:Longitudinal Aging Study Amsterdam frailty markers 


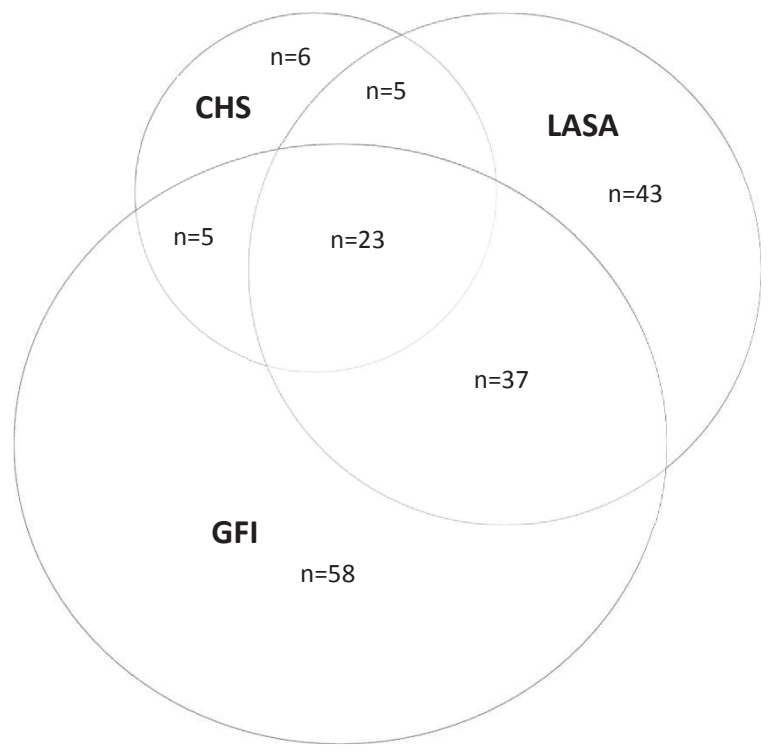

Figure 2: Venn diagram presenting the extent of overlap between the frail participants identified with the three frailty tools (the 177 participants in this diagram are those identified as frail by at least one of the tools)

CHS: Cardiovascular Health Study frailty phenotype; GFI: Groeningen Frailty Indicator, LASA:Longitudinal Aging Study Amsterdam frailty markers 

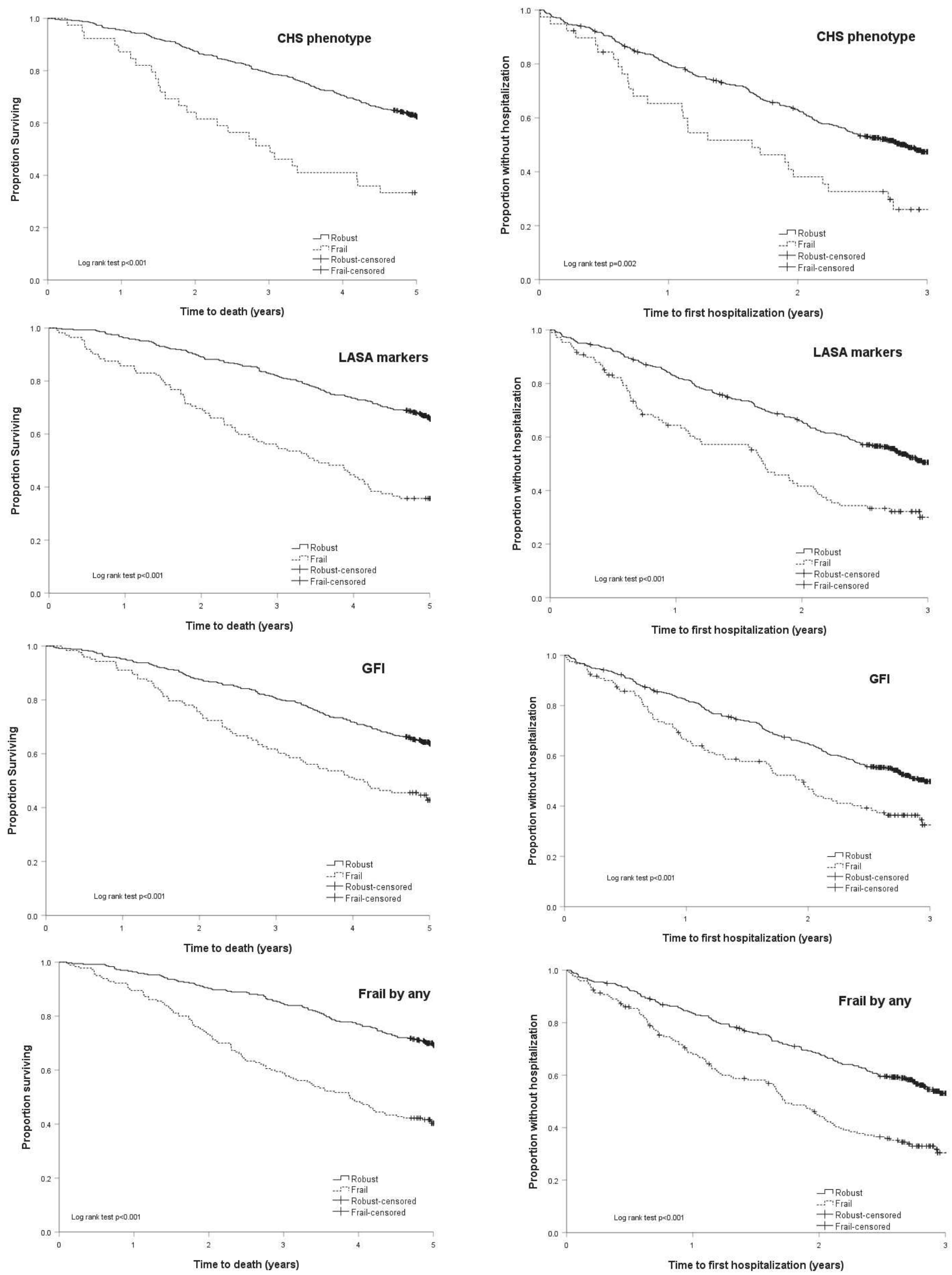

Figure 3: Kaplan-Meier survival curves for 5-years mortality and 3-years hospitalization for frailty by the different tools

CHS: Cardiovascular Health Study; LASA: Longitudinal Amsterdam Study of Ageing;GFI: Groeningen Frailty Indicator. Frail by any: if frail by any of the three tools. 

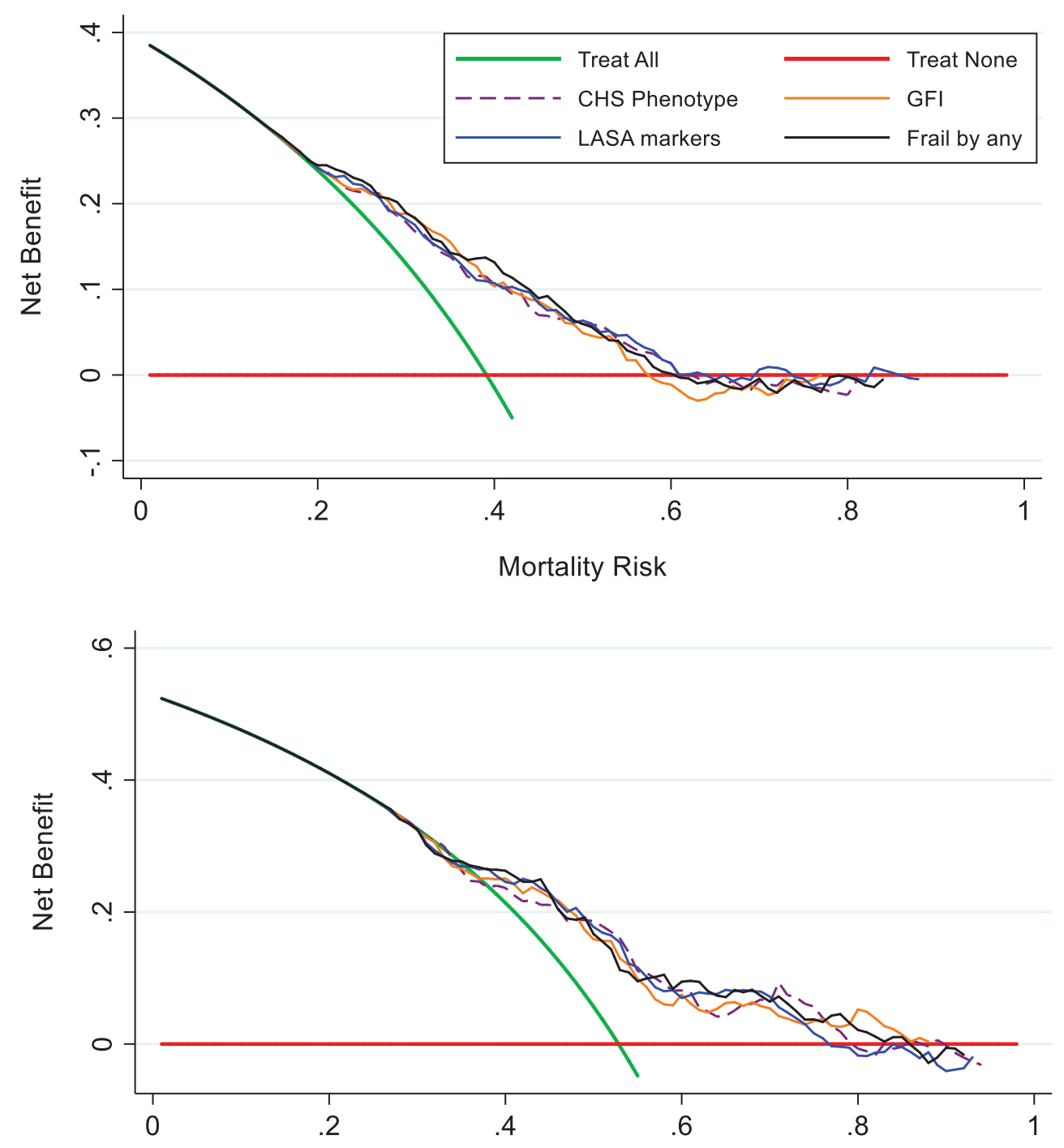

Risk for first hospitalization

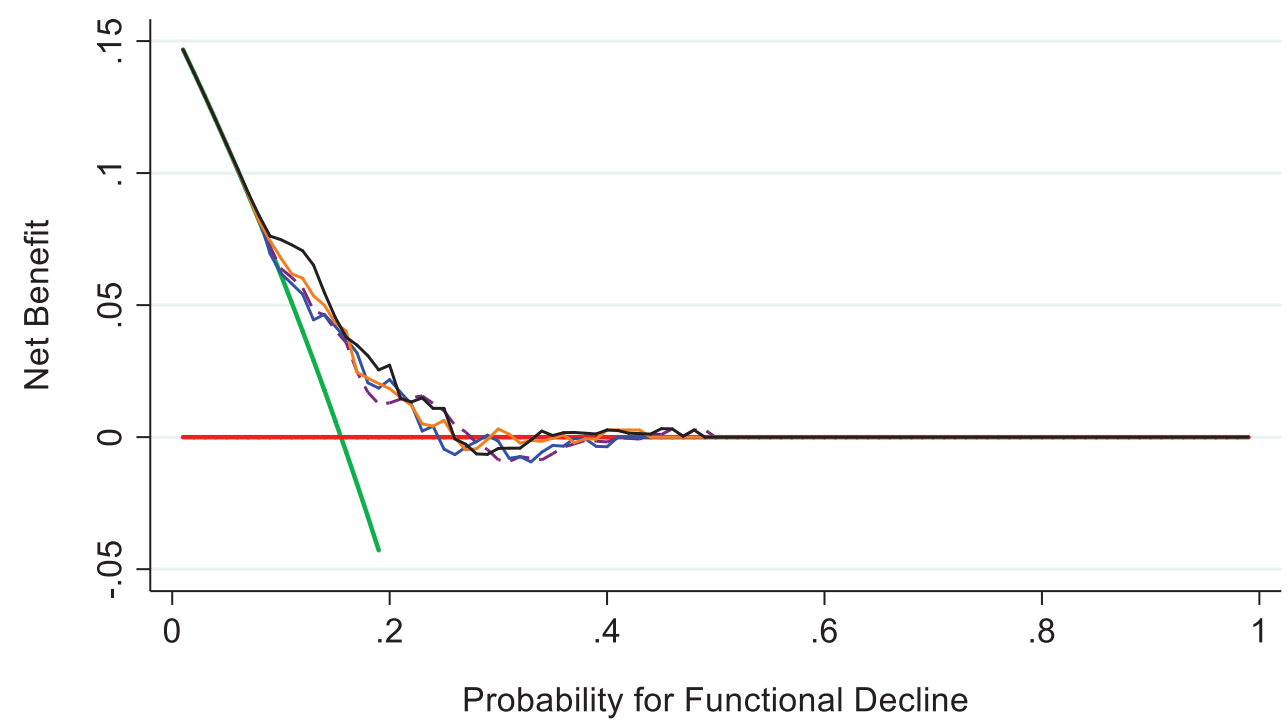

Figure 4: Decision curve analysis of frailty tools for mortality, hospitalization and functional decline Net benefit curves are plotted across risk/probability thresholds for an event (mortality, hospitalization, functional decline) for 6 options: 'treat all' as if they are frail, 'treat none' considering none is frail, treat according to frailty by CHS phenotype, LASA markers, GFI or if frail by any tool. 
Table 1: Baseline characteristics and outcomes of the study population in total and by frail categories according to each tool

\begin{tabular}{|c|c|c|c|c|c|c|c|c|c|c|}
\hline & & \multicolumn{3}{|c|}{ CHS Phenotype } & \multicolumn{3}{|c|}{ GFI } & \multicolumn{3}{|c|}{ LASA markers } \\
\hline & $\begin{array}{c}\text { Total } \\
(n=560)\end{array}$ & $\begin{array}{l}\text { Frail } \\
(n=39)\end{array}$ & $\begin{array}{l}\text { Robust } \\
(n=493)\end{array}$ & $P$ value & $\begin{array}{c}\text { Frail } \\
(n=123)\end{array}$ & $\begin{array}{l}\text { Robust } \\
(n=436)\end{array}$ & $P$ value & $\begin{array}{c}\text { Frail } \\
(n=108)\end{array}$ & $\begin{array}{l}\text { Robust } \\
(n=393)\end{array}$ & $P$ value \\
\hline Age years & $84.7 \pm 3.7$ & $86.5 \pm 4.8$ & $84.5 \pm 3.5$ & $0.001^{a}$ & $85.8 \pm 4.1$ & $84.4 \pm 3.5$ & $<0.001^{a}$ & $86.0 \pm 4$ & $84.4 \pm 3.5$ & $<0.001^{a}$ \\
\hline Sex male & 209 (37.3) & $18(46.2)$ & 183(37.1) & $0.263^{b}$ & $24(19.5)$ & $184(42.2)$ & $<0.001^{b}$ & $30(27.8)$ & $156(39.6)$ & $0.025^{b}$ \\
\hline BMI kg/m² & $27.4 \pm 4.9$ & $27.3 \pm 5.4$ & $1.61 \pm 0.09$ & $0.926^{a}$ & $27.2 \pm 5.5$ & $27.5 \pm 4.7$ & $0.556^{a}$ & $27.1 \pm 6.7$ & $27.5 \pm 4.3$ & $0.481^{a}$ \\
\hline ADL score & $25[21 ; 27]$ & $17[12 ; 20]$ & $25[22 ; 27]$ & $<0.001^{\mathrm{c}}$ & $19[14 ; 24]$ & $26[22 ; 29]$ & $<0.001^{\mathrm{c}}$ & $\begin{array}{c}19.5 \\
{[14 ; 25]}\end{array}$ & $26[22 ; 28]$ & $<0.001^{c}$ \\
\hline LAPAQ score & $61[18 ; 98]$ & $8[0 ; 28]$ & $70[29 ; 102]$ & $<0.001^{c}$ & $18[0 ; 58]$ & $71[31 ; 104]$ & $<0.001^{\mathrm{c}}$ & $16[16 ; 56]$ & $76[40 ; 106]$ & $<0.001^{\mathrm{c}}$ \\
\hline MMSE score & $28[25 ; 29]$ & $26[22 ; 28]$ & $28[26 ; 29]$ & $0.003^{c}$ & $26[22 ; 28]$ & $28[26 ; 29]$ & $<0.001^{\mathrm{c}}$ & $\begin{array}{c}25.5 \\
{[22 ; 28]}\end{array}$ & $\begin{array}{c}28 \\
{[26 ; 29]}\end{array}$ & $<0.001^{c}$ \\
\hline GDS-15 score & $2[1 ; 4]$ & $6[3 ; 8]$ & $2[1 ; 4]$ & $<0.001^{\mathrm{c}}$ & $5[3 ; 7]$ & $2[1 ; 3]$ & $<0.001^{\mathrm{c}}$ & $5[2 ; 7]$ & $2[1 ; 3]$ & $<0.001^{c}$ \\
\hline Disease count & $4[3 ; 5]$ & $4[3 ; 6]$ & $4[2 ; 5]$ & $0.276^{c}$ & $4[3 ; 6]$ & $4[2 ; 5]$ & $0.005^{c}$ & $5[3 ; 7]$ & $4[2 ; 5]$ & $<0.001^{\mathrm{c}}$ \\
\hline Grip strength & $\begin{array}{c}20.9 \\
{[15.8 ; 27.1]}\end{array}$ & $\begin{array}{c}14.8 \\
{[10.8 ; 19.1]}\end{array}$ & $\begin{array}{c}21.4 \\
{[16.8 ; 27.7]}\end{array}$ & $<0.001^{\mathrm{c}}$ & $\begin{array}{c}16.5 \\
{[13.3 ; 20.7]}\end{array}$ & $\begin{array}{c}22.5 \\
{[17.2 ; 29.2]}\end{array}$ & $<0.001^{\mathrm{c}}$ & $\begin{array}{c}16.8 \\
{[13.2 ; 20.9]}\end{array}$ & $\begin{array}{c}22 \\
{[17 ; 29]}\end{array}$ & $<0.001^{c}$ \\
\hline $\begin{array}{l}\text { Walking time* } \\
\text { seconds }\end{array}$ & $\begin{array}{c}10.9 \\
{[8.0 ; 14.7]}\end{array}$ & $\begin{array}{c}19.8 \\
{[14.3 ; 26.6]}\end{array}$ & $\begin{array}{c}10.5 \\
{[8.0 ; 13.7]}\end{array}$ & $<0.001^{c}$ & $\begin{array}{c}13.4 \\
{[9.3 ; 20.9]}\end{array}$ & $\begin{array}{c}10.4 \\
{[7.7 ; 13.5]}\end{array}$ & $<0.001^{c}$ & $\begin{array}{c}14.2 \\
{[11.1 ; 21.4]}\end{array}$ & $\begin{array}{c}10.6 \\
[8.0 ;) 13.7]\end{array}$ & $<0.001^{c}$ \\
\hline Death & $237(42.3)$ & $26(66.7)$ & 192 (38.9) & $0.001^{b}$ & $72(58.5)$ & $164(37.6)$ & $<0.001^{b}$ & 69(63.9) & $139(35.4)$ & $<0.001^{b}$ \\
\hline First hospitalization & $284(50.7)$ & $27(69.2)$ & 246 (50.5) & $0.030^{b}$ & $74(61.7)$ & $210(48.6)$ & $0.013^{b}$ & $69(65)$ & $108(46.4)$ & $0.001^{b}$ \\
\hline ADL decline & $66(15.7)$ & $7(35)$ & $54(14)$ & $0.019^{b}$ & $20(25)$ & $46(13.5)$ & $0.016^{b}$ & $17(23.9)$ & $44(14.1)$ & $0.048^{b}$ \\
\hline
\end{tabular}

Data are presented as mean \pm standard deviation, number (\%) or median [interquartile range]. ADL: activities of daily living; LAPAQ: LASA Physical Activity Questionnaire; MMSE: mini-mental state examination; GDS: geriatric depression scale; CHS: Cardiovascular Health Study; LASA: Longitudinal Ageing Study Amsterdam; GFI: Groeningen Frailty Indicator. ${ }^{*}$ Time to walk 3 meters, turn around and walk back as fast as possible. ${ }^{\text {a }}$ v value based on the Student's t-test: ${ }^{\mathrm{b}} \mathrm{P}$ value based on Pearson Chi-square test: ${ }^{\mathrm{C}} \mathrm{P}$ value based on the Mann-Whitney $\mathrm{U}$ test 
Table 2: Association of frailty by each of the three tools with mortality, hospitalization and functional decline

\begin{tabular}{|c|c|c|c|c|c|c|c|c|c|c|c|c|}
\hline \multirow{2}{*}{\multicolumn{2}{|c|}{$\mathrm{N}$}} & \multicolumn{3}{|c|}{ Mortality } & \multicolumn{4}{|c|}{ Hospitalization } & \multicolumn{4}{|c|}{ Functional decline } \\
\hline & & $\begin{array}{c}\text { crude HR } \\
(95 \% \mathrm{Cl})\end{array}$ & $\begin{array}{c}\text { adjusted HR } \\
(95 \% \mathrm{Cl})\end{array}$ & $\begin{array}{c}\text { Harrell's C } \\
(95 \% \mathrm{CI})\end{array}$ & $\mathrm{Nr}$ & $\begin{array}{c}\text { crude HR } \\
(95 \% \mathrm{Cl})\end{array}$ & $\begin{array}{c}\text { adjusted HR } \\
(95 \% \mathrm{Cl})\end{array}$ & $\begin{array}{c}\text { Harrell's C } \\
(95 \% \mathrm{Cl})\end{array}$ & $\mathrm{Nr}$ & $\begin{array}{c}\text { crude OR } \\
(95 \% \mathrm{Cl})\end{array}$ & $\begin{array}{c}\text { adjusted OR } \\
(95 \% \mathrm{Cl})\end{array}$ & $\begin{array}{c}\text { AUC } \\
(95 \% \mathrm{Cl})\end{array}$ \\
\hline CHS & 532 & $\begin{array}{c}2.52 \\
(1.67-3.80)\end{array}$ & $\begin{array}{c}1.84 \\
(1.20-2.82)\end{array}$ & $\begin{array}{c}0.65 \\
(0.61-0.69)\end{array}$ & 523 & $\begin{array}{c}1.85 \\
(1.24-2.76)\end{array}$ & $\begin{array}{c}1.63 \\
(1.08-2.45)\end{array}$ & $\begin{array}{c}0.64 \\
(0.61-0.68)\end{array}$ & 406 & $\begin{array}{c}3.31 \\
(1.26-8.67)\end{array}$ & $\begin{array}{c}2.59 \\
(0.95-7.02)\end{array}$ & $\begin{array}{c}0.66 \\
(0.58-0.73)\end{array}$ \\
\hline LASA & 501 & $\begin{array}{c}2.40 \\
(1.80-3.21)\end{array}$ & $\begin{array}{c}1.93 \\
(1.43-2.61)\end{array}$ & $\begin{array}{c}0.66 \\
(0.62-0.70)\end{array}$ & 491 & $\begin{array}{c}1.94 \\
(1.47-2.58)\end{array}$ & $\begin{array}{c}1.63 \\
(1.21-2.20)\end{array}$ & $\begin{array}{c}0.65 \\
(0.62-0.69)\end{array}$ & 384 & $\begin{array}{c}1.93 \\
(1.02-3.62)\end{array}$ & $\begin{array}{c}1.69 \\
(0.88-3.28)\end{array}$ & $\begin{array}{c}0.65 \\
(0.57-0.73)\end{array}$ \\
\hline GFI & 559 & $\begin{array}{c}1.90 \\
(1.44-2.51)\end{array}$ & $\begin{array}{c}1.62 \\
(1.21-2.16)\end{array}$ & $\begin{array}{c}0.65 \\
(0.61-0.68)\end{array}$ & 549 & $\begin{array}{c}1.61 \\
(1.24-2.10)\end{array}$ & $\begin{array}{c}1.54 \\
(1.16-2.04)\end{array}$ & $\begin{array}{c}0.64 \\
(0.61-0.68)\end{array}$ & 421 & $\begin{array}{c}2.14 \\
(1.18-3.87)\end{array}$ & $\begin{array}{c}2.05 \\
(1.10-3.80)\end{array}$ & $\begin{array}{c}0.67 \\
(0.59-0.74)\end{array}$ \\
\hline $\begin{array}{l}\text { Frail } \\
\text { by any }\end{array}$ & 541 & $\begin{array}{c}2.48 \\
(1.91-3.22)\end{array}$ & $\begin{array}{c}2.09 \\
(1.58-2.77)\end{array}$ & $\begin{array}{c}0.67 \\
(0.63-0.70)\end{array}$ & 531 & $\begin{array}{c}1.95 \\
(1.53-2.49)\end{array}$ & $\begin{array}{c}1.75 \\
(1.35-2.28)\end{array}$ & $\begin{array}{c}0.65 \\
(0.62-0.69)\end{array}$ & 411 & $\begin{array}{c}2.78 \\
(1.60-4.84)\end{array}$ & $\begin{array}{c}2.83 \\
(1.57-5.13)\end{array}$ & $\begin{array}{c}0.69 \\
(0.62-0.76)\end{array}$ \\
\hline
\end{tabular}

Nr: number of participants with all data for the analysis; HR: hazard ratio; OR: odds ratio; Cl: confidence interval; Adjusted HR/OR: adjusted for age, sex, multimorbidity; AUC: area under the receiver operating characteristics curve; CHS: Cardiovascular Health Study frailty phenotype ; LASA: Longitudinal Ageing Study Amsterdam frailty markers;GFI: Groeningen Frailty Indicator. Frail by any: if frail by any of the three tools. Reference group: robust group of the population for each tool. 
Table 3: Reclassification improvement statistics of the frailty tools for all-cause mortality, hospitalization and functional decline

\begin{tabular}{lccccc} 
& $\begin{array}{c}\text { NRI } \\
(95 \% \mathrm{Cl})\end{array}$ & $\begin{array}{c}\text { NRI } \\
\text { events } \\
\%\end{array}$ & $\begin{array}{c}\text { NRI } \\
\text { non-events } \\
\%\end{array}$ & $\begin{array}{c}\text { IDI } \\
(95 \% \mathrm{Cl})\end{array}$ & $\begin{array}{c}\text { relative } \\
\text { IDI }\end{array}$ \\
\hline CHS & Reference tool & & Mortality & & \\
& & & & & \\
LASA & 0.25 & -49.5 & 75 & 0.029 & 0.316 \\
& $(0.11 ; 0.41)$ & & & $(0.018 ; 0.040)$ & \\
GFI & -0.03 & -36.9 & 33.7 & 0.005 & 0.052 \\
& $(-0.20 ; 0.14)$ & & & $(-0.002 ; 0.012)$ & \\
Frail by & 0.40 & -21 & 60.9 & 0.041 & 0.462 \\
any & $(0.24 ; 0.56)$ & & & $(0.031 ; 0.051)$ & \\
\hline
\end{tabular}

Hospitalization

CHS Reference tool

\begin{tabular}{lccccc} 
LASA & 0.16 & -64 & 80.2 & 0.017 & 0.184 \\
& $(0.02 ; 0.30)$ & & & $(0.011 ; 0.025)$ & \\
GFI & -0.07 & -44.3 & 37.7 & -0.0004 & -0.005 \\
& $(-0.23 ; 0.09)$ & & & $(-0.006 ; 0.005)$ & \\
$\begin{array}{l}\text { Frail by } \\
\text { any }\end{array}$ & 0.16 & -35.9 & 51.4 & 0.017 & 0.182 \\
\hline
\end{tabular}

\section{Functional Decline}

$\begin{array}{lccccc}\text { CHS } & \text { Reference tool } & & & & \\ & & & & & \\ \text { LASA } & -0.008 & 1.75 & -2.58 & -0.007 & -6.903 \\ & (-0.29 ; 0.27) & & & (-0.012 ;-0.003) & \\ \text { GFI } & -0.05 & -20.0 & 14.9 & -0.006 & -7.450 \\ & (-0.32 ; 0.22) & & & (-0.010 ;-0.001) & \\ \text { Frail by } & 0.34 & -23.3 & 57.5 & 0.004 & -7.745 \\ \text { any } & (0.08 ; 0.60) & & & (-0.002 ; 0.010) & \end{array}$

NRI: continuous net reclassification index; IDI: integrative discrimination index. CHS: Cardiovascular Health Study frailty phenotype; LASA: Longitudinal Ageing Study Amsterdam frailty markers; GFI: Groeningen Frailty Indicator. Frail by any: if frail by any of the three tools. 
Click here to access/download Supplementary Material Appendix.docx 